\title{
Evaluation of Titanium Carbide Specimens for Microanalysis Reference Standards
}

\author{
R. B. Marinenko
}

National Institute of Standards and Technology, MS 8371, 100 Bureau Drive, Gaithersburg, MD 20899

Titanium carbide, an extremely hard, strong, and high melting material, is frequently used as a coating for cutting tools and armor and as a structural material for dies and tool parts. Stoichiometric $\mathrm{TiC}$ has a cubic structure, but the material most frequently exists in a substoichiometric form [1] in which there are carbon vacancies in the sublattice. The phase diagram have been reported by Storms [2].

Electron probe microanalysis (EPMA) of TiC specimens with unknown compositions requires a reference standard of known carbon composition. The use of area peak factor (APF) calculations described by Bastin [3] for the carbon analysis was considered. The $\mathrm{Fe}_{3} \mathrm{C}$ compound that he recommends as a reference standard was not readily available, and other available carbides were not known to be stoichiometric. Therefore, a $\mathrm{TiC}$ reference standard was considered to provide the minimum matrix corrections at the low excitation voltages required for the carbon analysis.

Three TiC candidate specimens, mounted in conducting media, polished but not carbon coated, were evaluated. EPMA data was acquired with wavelength dispersive spectrometers (WDS) using a PET crystal for titanium and a synthetic layered crystal, LDEC, for carbon. The first specimen (TiC \#1) was a powder that had been hot pressed. The second (TiC \#2) was an untreated powder with a range of particle sizes. The third (TiC \#3) was a piece of a single $\mathrm{TiC}$ crystal that was reported to be stoichiometric. In figures 1 and 2 are backscatter images taken at $15 \mathrm{kV}$ of specimens TiC \#1 and TiC \#2 respectively. The presence of multiple phases, none of which were sufficiently isolated to be sampled independently with the electron beam, can be seen in TiC \#1. A random point beam sampling with EPMA at $7.5 \mathrm{kV}$ of all of the apparent phases in the backscatter image gave an average $\mathrm{x}$-ray count rate reported in Table 1 with an expanded uncertainty $(\mathrm{k}=2$, $95 \%$ ) of more than $28 \%$ relative for carbon and $10 \%$ relative for titanium. Because of this large uncertainty and difficulty in independently sampling any phase, this specimen was eliminated as a practical reference standard.

Several large particles with dimensions of $8-10 \mu \mathrm{m}$ are present in TiC \#2. These could be independently analyzed with the electron beam. But the use of a particulate material as a reference standard requires the assurance that the electron beam samples only the interior of the particle. This means that data may have to be acquired manually if the reproducibility of an automated stage is not well within the particle dimensions. With careful sampling techniques, relative expanded uncertainties of $2.98 \%$ for carbon and $0.5 \%$ for titanium were obtained for TiC \#2 in Table 1 . For TC \#3, a bulk, polished material, there were no sampling problems. The relative expanded uncertainties for both titanium and carbon are $1.0 \%$ in a similar analysis using a $50 \mathrm{nA}$ current. 
Results of quantitative analysis of the TiC \#2 and TiC \# 3 with WDS-EPMA at $15 \mathrm{kV}$ and $20 \mathrm{kV}$ using a point beam and $40 \mathrm{~s}$ count times are reported in Table 2. A pure titanium reference standard was used while the carbon concentration was fixed at the stoichiometric value $(20.05 \%$ $\mathrm{mf}$ ) for the matrix correction calculations. Even if this concentration is not exactly correct, small modifications would have little impact on the measured titanium concentration that is, in fact, near the stoichiometric value (79.95\% mf) for both specimens as can be seen in the table. The components contributing to the relative expanded uncertainties in the table include those from the $\mathrm{TiC}$ samples and in the titanium reference standard. An additional systematic component from the matrix correction procedure that can only be estimated until there is a reliable bulk independent quantitative analysis of these specimens. This has not yet been added to these uncertainties.

\section{References}

[1] K. E. Tan et al., Mater. Sci. Eng. 5 (1997) 187.

[2] E. K. Storms, The Refractory Carbides, Academic Press, New York, 1967.

[3] G. F. Bastin and H. J. M. Heijligers, Microbeam Anal.-1984, San Francisco Press, Inc. San Francisco, 1984.

Table 1. WDS EPMA comparison of microheterogeneity of three TiC specimens using a point beam at $7.5 \mathrm{kV}$.

\begin{tabular}{|c|c|c|c|c|}
\hline \multirow{3}{*}{$\begin{array}{c}\text { Spec } \\
\#\end{array}$} & \multirow{3}{*}{$\begin{array}{l}\text { No. } \\
\text { points }\end{array}$} & \multirow{3}{*}{$\begin{array}{c}\text { Nominal } \\
\text { Current } \\
(\mathrm{nA})\end{array}$} & \multicolumn{2}{|c|}{$\begin{array}{l}\text { Current Corrected Counts/s } \\
\text { (Exp. Rel. Uncert. in Parenth.) }\end{array}$} \\
\hline & & & \multicolumn{2}{|c|}{ Element/X-ray line } \\
\hline & & & $\mathrm{CuK} \alpha$ & TiK $\alpha$ \\
\hline 1 & 17 & 100 & $8697(28.14)$ & $6821(10.12)$ \\
\hline 2 & 8 & 100 & $10375(2.98)$ & $6660(0.52)$ \\
\hline 3 & 10 & 50 & $4658(1.00)$ & $3747(1.00)$ \\
\hline
\end{tabular}

Table 2. WDS EPMA quantitative analysis of $\mathrm{TiK} \alpha$ in $\mathrm{TiC} \# 2$ and $\# 3$ at $15 \mathrm{kV}$ and $20 \mathrm{kV}$. C conc. specified at $20.05 \% \mathrm{mf}$.

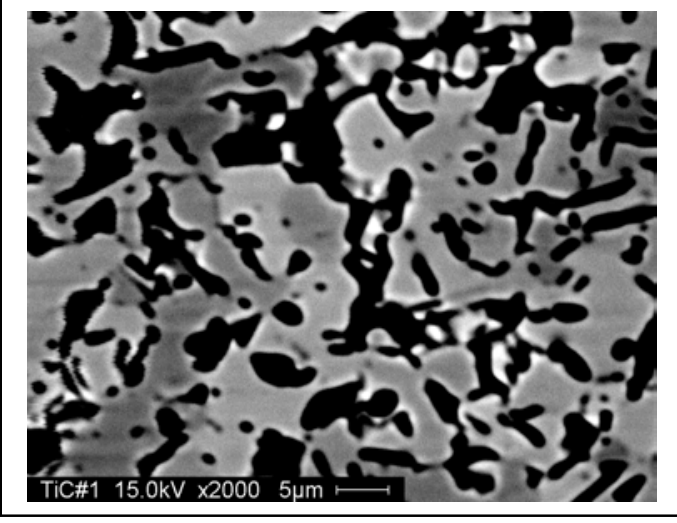

Fig.1. Backscatter image of TiC\#1,15 kV,2000x.

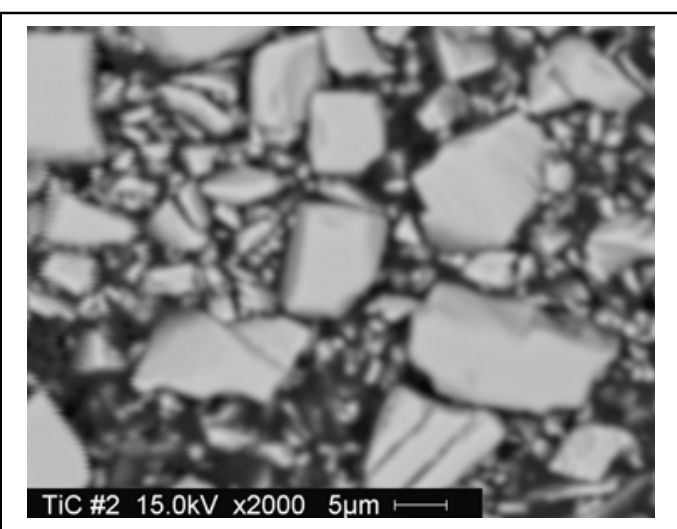

Fig 2. Backscatter image of $\mathrm{TiC} \# 2,15 \mathrm{kV}, 2000 \mathrm{x}$.

\begin{tabular}{|c|c|c|c|c|}
\hline \multirow{3}{*}{$\begin{array}{c}\text { Excit. } \\
\text { Pot. } \\
(\mathrm{kV})\end{array}$} & \multicolumn{3}{|c|}{ TiK $\alpha$ conc. in \% mf (Expanded rel. uncert. in parentheses) } \\
\cline { 2 - 5 } & \multicolumn{3}{|c|}{ Matrix Correction Procedure* } \\
\cline { 2 - 5 } & Armst./LS*** & \multicolumn{2}{|c|}{ TiC \#2 } & \multicolumn{2}{c|}{ TiC \#3./DR*** } \\
\hline 15 & $78.12(0.42)$ & $78.20(0.42)$ & $79.74(0.85)$ & $79.83(0.85)$ \\
\hline 20 & & & $79.83(0.50)$ & $80.10(0.50)$ \\
\hline Avg. & & & 79.79 & 79.95 \\
\hline
\end{tabular}

*used LINEMU mass absorption coefficients for both procedures

LINEMU $=$ Henke $(1985<10 \mathrm{ckeV} /$ CITMU $>10 \mathrm{keV}$

**Armst/LS $=$ Armstrong/Love Scott Correction

***Hein/DR= Heinrich/Duncumb-Reed Correction 
https://doi.org/10.1017/S1431927606066311 Published online by Cambridge University Press 